\title{
Lodo de esgoto em atributos biológicos do solo e na nodulação e produção de soja
}

\author{
Carla Albuquerque de Souza ${ }^{(1)}$, Fábio Bueno dos Reis Junior ${ }^{(2)}$, lêda de Carvalho Mendes ${ }^{(2)}$, \\ Jorge Lemainski(2) e José Eurípedes da Silva(3)
} (1)Universidade de Brasília, Faculdade UnB Planaltina, Área Universitária № 1, Vila Nossa Senhora de Fátima, CEP $73300-000$ Planaltina, DF.
E-mail: carla.biologia@gmail.com ${ }^{(2)}$ Embrapa Cerrados, Rodovia BR 020 Km 18, Caixa Postal 08223, CEP $73310-970$ Planaltina, DF.
E-mail: fabio@cpac.embrapa.br, mendesi@cpac.embrapa.br, jlemainski@hotmail.com ${ }^{(3)}$ Embrapa Agroenergia, Parque Estação Biológica,
Avenida W3 Norte (Final) Caixa Postal 040315, CEP 70770-901 Brasília, DF. E-mail: jose.euripedes@embrapa.br

Resumo - O objetivo deste trabalho foi avaliar os efeitos da aplicação do lodo produzido pela Companhia de Saneamento Ambiental do Distrito Federal (Caesb) na nodulação e rendimento de grãos da soja e em atributos biológicos de um Latossolo Vermelho de Cerrado. O experimento foi conduzido por dois anos consecutivos em um delineamento experimental de blocos ao acaso com três repetições e nove tratamentos - um controle, quatro doses de lodo de esgoto e quatro doses de fertilizante mineral - aplicados apenas no primeiro ano de cultivo. Foram avaliados: a nodulação e a produtividade da soja, o carbono da biomassa microbiana, o carbono prontamente mineralizável e a atividade das enzimas beta-glicosidase, fosfatase ácida e arilsulfatase no solo. Nos dois anos agrícolas, o rendimento de grãos da soja foi inferior ao do tratamento com o fertilizante mineral somente na dose de $1,5 \mathrm{Mg} \mathrm{ha}^{-1}$ de lodo de esgoto. A aplicação do lodo de esgoto no primeiro ano de cultivo não

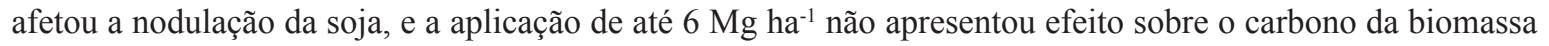
microbiana, o carbono prontamente mineralizável e a atividade das enzimas beta-glicosidase, arilsulfatase e fosfatase ácida do solo no período de dois anos.

Termos para indexação: Bradyrhizobium japonicum, Glycine max, atividade enzimática do solo, biomassa microbiana do solo, biossólido.

\section{Sewage sludge effects on soil biological parameters and on soybean nodulation and yield}

\begin{abstract}
The objective of this study was to evaluate the effects of applying sewage sludge produced by the Companhia de Saneamento Ambiental do Distrito Federal (Caesb) on the nodulation and yield of soybean and on the biological parameters of a Cerrado Oxisol. The experiment was done for two consecutive years in a completely randomized block design with three replicates and nine treatments - one control, four dosages of sewage sludge and four dosages of mineral fertilizer - applied only in the first year of the experiment. Soybean nodulation, grain yield, soil microbial biomass carbon, readily mineralizable carbon and activity of the beta-glucosidase, acid phosphatase and arylsulphatase enzymes were evaluated. In both years, the grain yield was lower than that of the mineral fertilizer only at the sewage sludge dose of $1.5 \mathrm{Mg} \mathrm{ha}^{-1}$. The application of sewage sludge in the first year of the crop does not affect soybean nodulation, and the application of up to $6 \mathrm{Mg} \mathrm{ha}^{-1}$ of sewage sludge had no effect on microbial biomass carbon, readily mineralizable carbon and on the activity of the beta-glucosidase, arylsulphatase and acid phosphatase soil enzymes in the two-year period.
\end{abstract}

Index terms: Bradyrhizobium japonicum, Glycine max, soil enzyme, activity, soil microbial biomass, biosolid.

\section{Introdução}

Lodo de esgoto ou biossólido é o resíduo do tratamento de esgoto, rico em matéria orgânica e nutrientes indispensáveis ao crescimento e ao desenvolvimento das plantas (Bettiol \& Camargo, 2000; Soares, 2005; Guedes et al., 2006). Para evitar o acúmulo desse lodo nas estações de tratamento de esgotos (ETEs), é comum o seu descarte em rios e mares, sua disposição em aterros sanitários ou sua incineração, o que causa efeitos deletérios ao meio ambiente, como eutrofização, poluição do solo, do ar e de lençóis freáticos (Bettiol \& Camargo, 2000). Uma opção ambientalmente sustentável para a disposição final do lodo de esgoto é seu uso como fertilizante e condicionador de solo na agricultura e em atividades florestais (Silva et al., 2002a, 2002b; Rocha et al., 2004; Trannin et al., 2005; Lemainski \& Silva, 2006a, 2006b). Para isso, o lodo de esgoto deve apresentar concentrações de agentes patogênicos e de

Pesq. agropec. bras., Brasília, v.44, n.10, p.1319-1327, out. 2009 
metais pesados abaixo dos limites estabelecidos pela Resolução Conama no 375/2006. Além disso, os efeitos da aplicação do lodo nos atributos químicos, físicos e biológicos do solo devem ser monitorados ao longo do tempo (Trannin et al., 2007, 2008).

A avaliação de indicadores microbiológicos como o carbono da biomassa microbiana do solo (CBM), o C prontamente mineralizável (C-mineralizável) e a atividade enzimática nas áreas tratadas com lodo vem sendo utilizada no monitoramento do impacto ambiental desse resíduo. Fernandes et al. (2005), utilizando lodo proveniente da estação de Barueri, SP, observaram aumentos no CBM, no C-mineralizável e nas atividades das enzimas amilase e urease, em função da aplicação de doses crescentes de lodo de esgoto.

Em um experimento em casa de vegetação utilizando lodo de esgoto contaminado com níquel, também oriundo da estação de tratamento de Barueri, SP, Revoredo \& Melo (2007) observaram que a atividade da fosfatase ácida diminuiu com o aumento da quantidade de níquel. Sastre et al. (1996), em um experimento de seis anos, compararam o efeito do lodo de esgoto de origem industrial e doméstica com o uso de fertilizante mineral sobre a atividade da enzima beta-glicosidase no solo e verificaram que essa atividade foi mais alta nos tratamentos com aplicação de lodo. No estudo de Kizilkaya \& Bayrakli (2005), foi observado um aumento na atividade das enzimas beta-glicosidase, urease, fosfatase alcalina e arilsulfatase nos tratamentos com doses entre 100 e $300 \mathrm{Mg} \mathrm{ha}^{-1}$ de lodo de esgoto oriundo de uma estação de tratamento na Turquia. Esse aumento ocorreu até os 30 dias após a incubação do lodo no solo e foi seguido por um drástico decréscimo nas avaliações posteriores. Os autores atribuíram o incremento inicial da atividade enzimática ao crescimento microbiano e à disponibilidade de substratos para as enzimas, estimulados pela adição do lodo de esgoto. Por outro lado, segundo os mesmos autores, o posterior decréscimo da atividade enzimática pode ter acontecido em resposta à concentração de metais presentes no lodo.

$\mathrm{Na}$ cultura da soja, a aplicação do lodo de esgoto pode interferir na fixação biológica de nitrogênio (FBN) devido a diversos fatores, entre eles os teores de metais pesados (Araujo, 2003) e de sais solúveis (Madariaga \& Angle, 1992) que podem ser encontrados em sua composição. Castilhos et al. (2001) observaram que a nodulação foi inibida nos tratamentos que continham lodo com quantidades altas de cádmio. No entanto, nos estudos de Vieira et al. (2001, 2004) e Araujo (2003), constatou-se que a aplicação de lodo de esgoto estimulou a nodulação, assim como a FBN, estimada por meio da avaliação da atividade da nitrogenase em ensaios de casa de vegetação. Currie et al. (2003) também demonstraram, em experimento realizado em campo, que a aplicação de lodo de esgoto pode incrementar as taxas de FBN na cultura da soja. Assim, é possível afirmar que efeitos positivos ou negativos sobre a nodulação e a FBN estão relacionados às características do resíduo utilizado.

Em Brasília, o lodo de esgoto, de origem predominantemente doméstica, é produzido pela Companhia de Saneamento Ambiental do Distrito Federal (Caesb) e atinge cerca de 400 toneladas diárias. Esse lodo, segundo a Resolução Conama no 375/2006 (Brasil, 2006), enquadra-se na Classe B com relação ao teor de microrganismos patogênicos, com concentração máxima de coliformes termotolerantes de $2 \times 10^{6}$ unidades formadoras de colônia por grama de matéria seca, e tem também baixa concentração de metais pesados, com valores inferiores aos limites estabelecidos pelas normas americanas e europeias (Luduvice, 2000). As características químicas do lodo de esgoto da Caesb foram apresentadas em detalhes por Lemainski \& Silva (2006b) e, em relação aos metais pesados, esse resíduo apresenta concentração de cádmio inferior a $2 \mathrm{mg} \mathrm{kg}^{-1}$, $50 \mathrm{mg} \mathrm{kg}^{-1}$ de chumbo, entre 48 e $56 \mathrm{mg} \mathrm{kg}^{-1}$ de mercúrio e entre 2,5 e $5,2 \mathrm{mg} \mathrm{kg}^{-1}$ de níquel. O desempenho agronômico e econômico desse lodo de esgoto também foi avaliado por Silva et al. (2002a, 2002b) e por Lemainski \& Silva (2006a, 2006b).

As características dos lodos de diferentes locais do país variam em função da época, do tipo de tratamento e da bacia de drenagem, e seu uso agrícola pode causar alterações nos atributos químicos, físicos e biológicos dos solos.

O objetivo deste trabalho foi comparar os efeitos da aplicação imediata e residual de doses crescentes de lodo de esgoto produzido pela Caesb com o uso de fertilizantes minerais e avaliar seus efeitos na nodulação e na produtividade da soja, bem como sobre os atributos biológicos de um Latossolo Vermelho de Cerrado.

\section{Material e Métodos}

O experimento foi realizado em campo, no período de 2004 a 2006, na Embrapa Cerrados, Planaltina, DF, em um Latossolo Vermelho de textura argilosa (520 $\mathrm{g} \mathrm{kg}^{-1}$ de argila), cujo histórico foi descrito detalhadamente por Lemainski \& Silva (2006a, 
2006b). A análise do solo (Claessen, 1997) na camada de 0 a $20 \mathrm{~cm}$, antes do primeiro cultivo, indicou: $\mathrm{pH}$ em água, 5,96; $\mathrm{P}, 3,12 \mathrm{mg} \mathrm{dm}{ }^{-3} ; \mathrm{Al}^{3+}, 0 \mathrm{mmol}_{\mathrm{c}} \mathrm{dm}^{-3}$; $\mathrm{H}+\mathrm{Al}, 33,2 \mathrm{mmol}_{\mathrm{c}} \mathrm{dm}^{-3} ; \mathrm{Ca}^{2+}+\mathrm{Mg}^{2+}, 53,3 \mathrm{mmol}_{\mathrm{c}} \mathrm{dm}^{-3}$; $\mathrm{K}^{+}, 76,6 \mathrm{mg} \mathrm{dm}^{-3}$ e $\mathrm{MO}, 26,9 \mathrm{~g} \mathrm{dm}^{-3}$.

$\mathrm{O}$ delineamento experimental empregado foi $\mathrm{o}$ de blocos ao acaso, com três repetições (parcelas de $9 \times 7 \mathrm{~m}$ ) e nove tratamentos (Tabela 1), quatro com doses crescentes de lodo de esgoto - de 1,5 a $6 \mathrm{Mg} \mathrm{ha}^{-1}$ (base seca) -, quatro com fertilizante mineral misto (em quantidades de $\mathrm{N}, \mathrm{P}_{2} \mathrm{O}_{5}$ e $\mathrm{K}_{2} \mathrm{O}$ equivalentes às de lodo de esgoto aplicado) e um tratamento controle sem lodo e sem fertilizante mineral. As doses de lodo de esgoto utilizadas foram com base no trabalho Lemainski \& Silva (2006b) visando, principalmente, o fornecimento de P para as plantas. Por ser uma leguminosa capaz de fixar o $\mathrm{N}$ atmosférico, quando em associação simbiótica com bactérias diazotróficas, o fósforo parece ser a parte mineral mais expressivo do lodo do esgoto para a soja.

O lodo utilizado neste trabalho foi produzido na ETE de Brasília, na Caesb Norte, e armazenado em depósito temporário junto à área experimental da Embrapa Cerrados. Esse material apresentava teor de água de $700 \mathrm{~g} \mathrm{~kg}^{-1}$, densidade de $0,90 \mathrm{~kg} \mathrm{~L}^{-1}$ e composição química apresentada na Tabela 2. Em 7/12/2004, o lodo de esgoto e o fertilizante mineral foram aplicados ao solo uniformemente a lanço, seguidos de incorporação com grade niveladora na profundidade de 0 a $10 \mathrm{~cm}$.

Tabela 1. Doses de lodo de esgoto (LE) - em base seca e fertilizante mineral (FM) misto de ureia, supertriplo e cloreto de potássio aplicadas em um Latossolo Vermelho de Cerrado, em Planaltina, DF, no primeiro ano de cultivo de soja (2004/2005).

\begin{tabular}{lcc}
\hline Tratamento & Doses $\left(\mathrm{Mg} \mathrm{ha}^{-1}\right)$ & $\mathrm{N}, \mathrm{P}_{2} \mathrm{O}_{5}$ e $\mathrm{K}_{2} \mathrm{O}\left(\mathrm{kg} \mathrm{ha}^{-1}\right)$ \\
\hline Controle & 0,0 & $00-00-00$ \\
LE1 & 1,5 & $99-101-07$ \\
LE2 & 3,0 & $196-200-14$ \\
LE3 & 4,5 & $295-301-22$ \\
LE4 & 6,0 & $393-402-29$ \\
FM1 & - & $99-101-07$ \\
FM2 & - & $196-200-14$ \\
FM3 & - & $295-301-22$ \\
FM4 & - & $393-402-29$ \\
\hline
\end{tabular}

Dois dias após a aplicação do lodo de esgoto e do fertilizante mineral, a soja foi plantada no solo preparado com aração e gradagem. No ano agrícola seguinte, não foram feitas aplicações de lodo de esgoto ou de fertilizantes para avaliar o efeito residual dos tratamentos aplicados no ano anterior sobre a produtividade da soja e os atributos biológicos do solo.

A cultivar de soja utilizada foi a BRS Raimunda, plantada no espaçamento de $45 \mathrm{~cm}$, com densidade de 18 plantas $\mathrm{m}^{-2}$. Antes dos dois plantios, as sementes foram inoculadas com as estirpes Bradyrhizobium japonicum SEMIA 5080 (CPAC 7) e SEMIA 5079 (CPAC 15) na proporção de $500 \mathrm{~g}$ de inoculante turfoso para $40 \mathrm{~kg}$ de semente.

As amostragens para avaliação da nodulação da soja foram feitas aos 60 dias após a germinação das sementes, na fase de floração, no primeiro e no segundo ano de cultivo. A parte aérea foi separada da raiz, os nódulos foram destacados, lavados e secos em estufa com ventilação forçada a $65^{\circ} \mathrm{C}$, até atingir massa constante e, em seguida, foram contados e pesados.

Para a avaliação dos atributos biológicos, amostras de solo foram coletadas também na fase de floração da soja nos dois anos de cultivo (março de 2005 e fevereiro de 2006), nas profundidades: 0 a $5 \mathrm{~cm}$, por meio de minitrincheiras com uso de um facão; e 5 a $20 \mathrm{~cm}$, com trado holandês. Em cada parcela, foram coletadas seis subamostras para formar uma amostra composta. As amostras de solo foram acondicionadas em sacos de plástico e mantidas em geladeira à temperatura de 7 a $10^{\circ} \mathrm{C}$ por até 72 horas. No laboratório, as amostras passaram por uma peneira com malha de $4 \mathrm{~mm}$ e os resíduos orgânicos, como plantas, raízes e sementes, foram removidos manualmente.

O CBM foi determinado pelo método de fumigação-extração (FE) proposto por Vance et al. (1987). Depois da coleta no campo, o teor de umidade das amostras de solo (20 g) foi elevado a 90\% da capacidade de campo quando necessário, e as amostras foram pré-incubadas no escuro por sete dias, à temperatura ambiente. Em seguida, metade das

Tabela 2. Características químicas do lodo de esgoto da Caesb (base seca) utilizado neste trabalho.

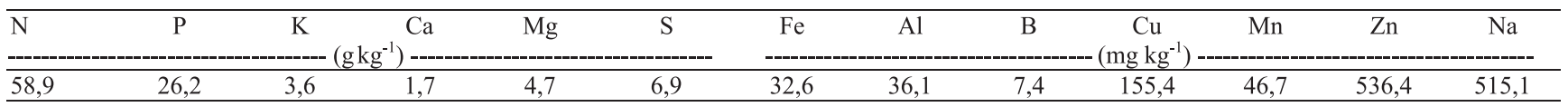


amostras de solo foi fumigada por 48 horas em um dessecador contendo uma placa de Petri com $25 \mathrm{~mL}$ de clorofórmio livre de álcool. Durante esse período, as amostras não fumigadas foram mantidas à temperatura ambiente. O carbono da biomassa microbiana foi extraído pela adição de $50 \mathrm{~mL}$ de uma solução de sulfato de potássio $\left(0,5 \mathrm{~mol} \mathrm{~L}^{-1}\right.$ de $\left.\mathrm{K}_{2} \mathrm{SO}_{4}\right)$ e determinado por titulação com uma solução de sulfato ferroso amoniacal $\left[\left(\mathrm{NH}_{4}\right)_{2} \mathrm{Fe}\left(\mathrm{SO}_{4}\right) 6 \mathrm{H}_{2} \mathrm{O}\right]$ em ácido sulfúrico concentrado, na presença de um indicador composto por fenantrolina $\left(0,075 \mathrm{~mol} \mathrm{~L}^{-1}\right)$ e sulfato ferroso $\left(0,041 \mathrm{~mol} \mathrm{~L}^{-1}\right)$. A quantidade de CBM foi determinada pela diferença entre o carbono orgânico extraído das amostras de solo fumigadas e não fumigadas usando um fator de correção $(\mathrm{Kec})$ igual a 0,35 . O carbono prontamente mineralizável foi estimado por meio da quantidade de gás carbônico liberado pelas amostras de solo não fumigado, incubadas por um período de sete dias (Oliveira et al., 2001). Essas amostras foram transferidas para recipientes de vidro com tampas rosqueáveis e capacidade de $500 \mathrm{~mL}$ contendo um frasco de vidro $(30 \mathrm{~mL})$ com $10 \mathrm{~mL}$ de $\mathrm{KOH}$ $0,3 \mathrm{~mol} \mathrm{~L}^{-1}$. A quantidade de $\mathrm{CO}_{2}$ liberada do solo foi determinada após titulação com $\mathrm{HCl} 0,1 \mathrm{~mol} \mathrm{~L}^{-1}$ usando fenolftaleína $1 \%$ como indicador. Aos frascos contendo o $\mathrm{KOH}$, foram adicionados $3 \mathrm{~mL}$ de $\mathrm{BaCl}_{2}$ $20 \%$ antes da titulação.

As atividades das enzimas do solo associadas ao ciclo do carbono (beta-glicosidase), do fósforo (fosfatase ácida) e do enxofre (arilsulfatase) foram determinadas utilizando-se os métodos descritos por Tabatabai (1994). Esses métodos baseiam-se na determinação colorimétrica do $p$-nitrofenol, de coloração amarela, formado após a adição de substratos incolores específicos para cada enzima avaliada (p-nitrofenil-beta-D-glicopiranosídeo, -nitrofenilfosfato e $p$-nitrofenil sulfato) para as enzimas beta-glicosidase, fosfatase ácida e arilsulfatase, respectivamente. Para cada amostra de solo coletada no campo, foram realizadas duas repetições analíticas no laboratório e seus controles (brancos). A atividade enzimática do solo foi expressa em $\mu \mathrm{g}$ de $p$-nitrofenol liberado por hora por grama de solo seco.

As análises de variância para cada ano agrícola foram efetuadas pelo SAS (SAS Institute, 1996), e as diferenças estatísticas foram determinadas pelo teste de Duncan, a 5\% de probabilidade. Para comparação dos efeitos decorrentes da aplicação do lodo de esgoto e do fertilizante mineral nos atributos microbiológicos do solo, contrastes não ortogonais também foram calculados e testados pelo teste $\mathrm{F}$, a $5 \%$ e $1 \%$ de significância.

\section{Resultados e Discussão}

$\mathrm{Na}$ avaliação feita no primeiro ano agrícola, os tratamentos com as doses mais elevadas de fertilizante mineral(FM3 e FM4) apresentaram reduções no número de nódulos (Tabela 3) e foram significativamente inferiores aos tratamentos com a menor dose de fertilizante (FM1) e à aplicação de $3 \mathrm{Mg} \mathrm{ha}^{-1}$ (LE2) e 4,5 $\mathrm{Mg} \mathrm{ha}^{-1}$ (LE3) de lodo de esgoto. $\mathrm{Na}$ maior dose aplicada de fertilizante mineral (FM4), também houve decréscimo generalizado na massa seca total dos nódulos, que foi significativamente inferior aos tratamentos controle, LE2, LE3 e FM1. Essas reduções refletem o efeito inibitório do nitrogênio aplicado na

Tabela 3. Número de nódulos por planta, massa seca de nódulos (mg por planta) e produtividade ( $\left.\mathrm{kg} \mathrm{ha}^{-1}\right)$ da soja cultivada nos anos agrícolas 2004/2005 e 2005/2006, em Latossolo Vermelho de Cerrado, adubado com lodo de esgoto e fertilizante mineral apenas no primeiro ano de cultivo ${ }^{(1)}$.

\begin{tabular}{|c|c|c|c|c|c|c|}
\hline \multirow[t]{2}{*}{ Tratamento } & \multicolumn{2}{|c|}{ Número nódulos por planta } & \multicolumn{2}{|c|}{ Massa seca de nódulos } & \multicolumn{2}{|c|}{ Produtividade } \\
\hline & $1^{0}$ ano & $2^{\circ}$ ano & $1^{\circ}$ ano & $2^{-}$ano & $1^{\underline{0}}$ ano & $2^{\underline{0}}$ ano \\
\hline Controle & $81 \mathrm{ab}$ & 46 & $200 a$ & 80 & $2.199 \mathrm{e}$ & $1.141 \mathrm{c}$ \\
\hline $\mathrm{LE}^{(2)}$ & $75 a b c$ & 51 & $171 \mathrm{ab}$ & 110 & $2.909 \mathrm{~d}$ & $1.504 \mathrm{c}$ \\
\hline LE2 & $106 a$ & 56 & $225 a$ & 130 & $3.380 \mathrm{bc}$ & $2.401 \mathrm{~b}$ \\
\hline LE3 & $96 a$ & 65 & $213 a$ & 140 & $3.582 \mathrm{abc}$ & $2.532 \mathrm{ab}$ \\
\hline LE4 & $70 \mathrm{abc}$ & 64 & $147 \mathrm{ab}$ & 180 & $3.675 \mathrm{abc}$ & $2.580 \mathrm{ab}$ \\
\hline$F M 1^{(3)}$ & $91 \mathrm{a}$ & 76 & $185 a$ & 150 & $3.345 \mathrm{c}$ & $2.238 b$ \\
\hline FM2 & $75 \mathrm{abc}$ & 71 & $131 \mathrm{ab}$ & 150 & $3.419 \mathrm{abc}$ & $2.419 b$ \\
\hline FM3 & $57 b c$ & 73 & $135 \mathrm{ab}$ & 190 & $3.736 \mathrm{ab}$ & $2.726 \mathrm{ab}$ \\
\hline FM4 & $48 \mathrm{c}$ & 55 & $88 b$ & 170 & $3.774 \mathrm{a}$ & $2.953 \mathrm{a}$ \\
\hline CV (\%) & 12 & 27 & 29 & 29 & 6 & 11 \\
\hline
\end{tabular}

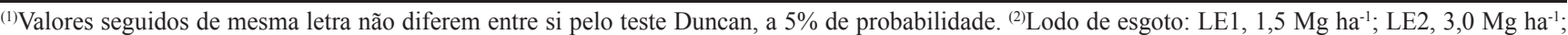
LE3, 4,5 $\mathrm{Mg} \mathrm{ha}^{-1}$; LE4, 6,0 $\mathrm{Mg} \mathrm{ha}^{-1} .{ }^{(3)}$ Fertilizante mineral (N; $\mathrm{P}_{2} \mathrm{O}_{5}$; K $\mathrm{K}_{2}$ ): FM1, 99-101-7 kg ha ${ }^{-1}$ FM2, 196-200-14 kg ha-1; FM3, 295-301-22 kg ha ${ }^{-1}$; FM4, 393-402-29 $\mathrm{kg} \mathrm{ha}^{-1}$. 
forma de ureia (Koutroubras et al., 1998; Mendes et al., 2003), o que não foi observado nos tratamentos com aplicação de lodo de esgoto, provavelmente devido ao fato de que, no lodo, o nitrogênio encontra-se em formas orgânicas e necessita ser mineralizado para que as plantas possam aproveitá-lo (Boeira \& Maximiliano, 2004). Nesse caso, o $\mathrm{N}$ é disponibilizado aos poucos, ao longo de todo o período de crescimento da planta e não apenas no início do desenvolvimento ou na floração, quando os nódulos estão sendo formados e a FBN atinge a sua taxa máxima (Currie et al., 2003). A fração de mineralização de $\mathrm{N}$ dos lodos de esgoto é variável conforme o material de origem e o processo de tratamento. Embora a taxa de mineralização de $\mathrm{N}$ do lodo de esgoto da Caesb não tenha sido determinada, Boeira et al. (2002) estimaram que apenas 31\% do N orgânico de um lodo de esgoto de origem estritamente urbana, oriundo de Franca, SP, foi mineralizado após 105 dias de incubação.

As reduções que ocorreram na nodulação não afetaram o rendimento de grãos, uma vez que tanto o fertilizante mineral quanto o lodo de esgoto funcionaram como fontes de N (Tabela 3). Conforme esperado, no primeiro ano, os menores valores de rendimento de grãos foram observados no tratamento controle, onde não houve aplicação de fontes extras de nutrientes sob a forma de lodo ou fertilizante, o que evidencia a baixa fertilidade natural do solo onde foi conduzido este estudo. Comparando-se as doses de lodo de esgoto e de fertilizante mineral, equivalentes em NPK, observou-se que apenas na dose de fertilizante mineral FM1 o rendimento de grãos foi superior ao da dose correspondente de lodo LE1 (1,5 $\left.\mathrm{Mg} \mathrm{ha}^{-1}\right)$. Nos demais tratamentos com doses equivalentes, as diferenças entre o lodo e o fertilizante mineral não foram significativas, o que demonstra a eficiência do uso do lodo de esgoto da Caesb como fertilizante para a cultura da soja. Tanto para o lodo de esgoto quanto para o fertilizante mineral, a produtividade obtida na dose 2 não diferiu estatisticamente da produtividade das doses 3 e 4 .

No segundo ano agrícola, quando se avaliou o efeito residual do lodo e do fertilizante mineral, as diferenças entre os tratamentos quanto aos valores de número e massa seca de nódulos não foram significativas. Em relação ao primeiro cultivo, observou-se uma redução entre 32 e $47 \%$ no número de nódulos por planta e entre 34 e $60 \%$ na massa seca de nódulos por planta nos tratamentos controle e com lodo de esgoto nas doses 1, 2 e 3 (LE1, LE2 e LE3), provavelmente como consequência da depleção de nutrientes. Isso também fez com que o rendimento de grãos obtido no segundo ano de cultivo fosse reduzido entre $22 \mathrm{e}$ $48 \%$, dependendo do tratamento. Como observado no primeiro ano do experimento, apenas na dose 1 a produtividade da soja com a aplicação do fertilizante mineral (FM1) foi superior à do lodo de esgoto (LE1). Nas demais doses, não houve diferenças entre o lodo e o fertilizante mineral; em relação ao tratamento controle, o efeito residual médio desses produtos para as doses 2, 3 e 4 resultou em incrementos da ordem de 111, 130 e $142 \%$, respectivamente, no rendimento da soja. Para o lodo de esgoto, não houve diferenças entre as doses 2, 3 e 4. Entretanto, para o fertilizante mineral, a dose 4 diferiu significativamente da dose 2 .

Resultados semelhantes, que evidenciam o efeito benéfico da aplicação imediata e residual do lodo da Caesb em milho e soja, foram reportados por Lemainski \& Silva (2006a, b). Após a análise de eficiência agronômica, esses autores observaram que o lodo de esgoto foi, em média, 21 e $18 \%$ mais eficiente em cultivos de milho e soja, respectivamente, que as fontes minerais de nutrientes, o que revela a viabilidade de sua utilização como fertilizante na produção de grãos no Distrito Federal.

As respostas dos atributos biológicos do solo à aplicação de lodo de esgoto foram analisadas pela comparação individual das médias (Tabela 4) e pelo teste dos contrastes (Tabela 5). Apenas no segundo ano agrícola (2005/2006), quando se avaliou o efeito residual da aplicação do lodo de esgoto e do fertilizante mineral, foram observadas algumas diferenças pontuais nos atributos biológicos do solo.

A aplicação de 4,5 $\mathrm{Mg} \mathrm{ha}^{-1}$ de lodo de esgoto (LE3) na profundidade 0 a $5 \mathrm{~cm}$ foi o único tratamento a apresentar maior CBM que o controle absoluto, e foi superior também aos tratamentos com a menor dose de lodo (LE1) e com as doses 3 e 4 (FM3 e FM4) de fertilizante mineral (Tabela 4). Fernandes et al. (2005), utilizando lodo de esgoto oriundo da estação de tratamento de Barueri, São Paulo, para o plantio de milho, observaram aumentos no CBM e no C-mineralizável com o aumento das doses de lodo de esgoto, que variaram de 3,99 $\mathrm{Mg} \mathrm{ha}^{-1}$ a $64,76 \mathrm{Mg} \mathrm{ha}^{-1}$, aplicadas anualmente durante um período de quatro anos. Assim, os aumentos do CBM e do C-mineralizável foram associados aos incrementos de matéria orgânica 
que ocorreram em função do aumento das doses de lodo. Em contrapartida, Sullivan et al. (2006), ao trabalhar com doses entre 2,5 e $30 \mathrm{Mg} \mathrm{ha}^{-1}$, não observaram alterações na biomassa microbiana total como efeito da aplicação de lodo de esgoto e sugeriram que, nesse caso, houve rápida adaptação da microbiota do solo.

Efeitos negativos sobre os atributos biológicos do solo, como o CBM, em função da utilização de doses de lodo contaminado com metais pesados são reportados na literatura (Kizilkaya \& Bayrakli, 2005) e evidenciam os impactos nocivos desses elementos químicos nas comunidades microbianas. Dar (1996), por exemplo, utilizou lodo contaminado com cádmio e observou que o CBM decresceu rapidamente quando a concentração desse elemento chegou a $50 \mu \mathrm{g} \mathrm{g}^{-1}$ solo. Como o lodo de esgoto da Caesb contém baixas quantidades de metais pesados (Luduvice, 2000; Lemainski \& Silva, 2006a), tais efeitos deletérios não foram observados neste trabalho. Além disso, a quantidade de lodo utilizada, pequena em comparação com a maioria dos trabalhos e aplicada por apenas um ano, também deve ser considerada.
$\mathrm{Na}$ profundidade de 0 a $5 \mathrm{~cm}$, o solo adubado com a dose de fertilizante mineral (FM4) apresentou menor atividade da fosfatase ácida em comparação aos demais tratamentos, com exceção de FM3 (Tabela 4). Isso pode ser explicado pela maior disponibilidade de P solúvel nesses tratamentos, o que inibe a ação dessa enzima (Tabatabai, 1994). Além disso, a atividade da fosfatase ácida na profundidade de 0 a $5 \mathrm{~cm}$, no segundo ano agrícola, foi o único parâmetro que apresentou significância estatística para o contraste entre a aplicação de lodo de esgoto e de fertilizante mineral (Tabela 5). Observou-se, por meio desse contraste, que a atividade dessa enzima foi maior na presença do lodo de esgoto em comparação ao fertilizante mineral, possivelmente devido à presença de $\mathrm{P}$ orgânico nesse material. Moreno et al. (1998), em experimento com lentilha e cevada em casa de vegetação, também verificaram que a atividade da fosfatase foi maior nos tratamentos com lodo e atribuíram esse efeito à presença de substratos com fósforo orgânico, que induzem a síntese dessa enzima.

A análise de contrastes revelou diferenças entre a aplicação de lodo de esgoto e de doses equivalentes

Tabela 4. Carbono da biomassa microbiana do solo (CBM, $\mathrm{mg} \mathrm{C} \mathrm{kg}^{-1}$ solo), carbono prontamente mineralizável (C-mineralizável, $\mathrm{mg} \mathrm{C} \mathrm{kg}{ }^{-1}$ solo) e atividade das enzimas beta-glicosidase, fosfatase ácida e arilsulfatase ( $\mu \mathrm{g} \mathrm{p}$-nitrofenol $\mathrm{g}^{-1}$ solo ha $\mathrm{h}^{-1}$ ), avaliados nos anos agrícolas 2004/2005 e 2005/2006, em amostras de um Latossolo Vermelho de Cerrado coletadas na profundidade de 0 a 5 e 5 a $20 \mathrm{~cm}$, adubadas com lodo de esgoto e fertilizante mineral apenas no primeiro ano de cultivo da soja ${ }^{(1)}$.

\begin{tabular}{|c|c|c|c|c|c|c|c|c|c|c|}
\hline \multirow[t]{2}{*}{ Tratamento } & \multicolumn{2}{|c|}{ CBM } & \multicolumn{2}{|c|}{ C-mineralizável } & \multicolumn{2}{|c|}{$\beta$-glicosidase } & \multicolumn{2}{|c|}{ Fosfatase ácida } & \multicolumn{2}{|c|}{ Arilsulfatase } \\
\hline & $1^{\circ}$ ano & $2^{\circ}$ ano & $1^{\circ}$ ano & $2^{\circ}$ ano & $1^{\circ}$ ano & $2^{-}$ano & $1^{\circ}$ ano & $2^{\circ}$ ano & $1^{\circ}$ ano & $2^{\circ}$ ano \\
\hline & \multicolumn{10}{|c|}{0 a $5 \mathrm{~cm}$} \\
\hline Controle & 240 & $340 \mathrm{bc}$ & 65 & 76 & 97 & $119 b c$ & 595 & $563 \mathrm{ab}$ & 64 & 50 \\
\hline $\mathrm{LE}^{(2)}$ & 227 & $255 \mathrm{c}$ & 70 & 81 & 96 & $118 b c$ & 551 & $567 \mathrm{ab}$ & 59 & 52 \\
\hline LE2 & 198 & $428 \mathrm{ab}$ & 84 & 96 & 96 & $130 \mathrm{ab}$ & 507 & $613 a$ & 62 & 53 \\
\hline LE3 & 245 & $523 a$ & 78 & 74 & 91 & $127 \mathrm{ab}$ & 496 & $574 \mathrm{ab}$ & 57 & 52 \\
\hline LE4 & 230 & $397 \mathrm{abc}$ & 87 & 68 & 97 & $115 b c$ & 491 & $572 \mathrm{ab}$ & 58 & 50 \\
\hline $\mathrm{FM} 1^{(3)}$ & 270 & $388 \mathrm{abc}$ & 89 & 74 & 90 & $149 a$ & 484 & $584 \mathrm{ab}$ & 55 & 55 \\
\hline FM2 & 242 & $413 \mathrm{ab}$ & 76 & 73 & 92 & $116 \mathrm{bc}$ & 484 & $559 \mathrm{ab}$ & 54 & 53 \\
\hline FM3 & 201 & $371 b c$ & 66 & 73 & 98 & $101 \mathrm{c}$ & 554 & $520 \mathrm{bc}$ & 60 & 51 \\
\hline FM4 & 176 & $369 \mathrm{bc}$ & 74 & 62 & 101 & $111 \mathrm{bc}$ & 544 & $461 \mathrm{c}$ & 68 & 44 \\
\hline \multirow[t]{2}{*}{ CV (\%) } & 40 & 18 & 16 & 27 & 10 & 11 & 10 & 7 & 10 & 11 \\
\hline & \multicolumn{10}{|c|}{5 a $20 \mathrm{~cm}$} \\
\hline Controle & 318 & 304 & 80 & 56 & 86 & $95 b c$ & 491 & 656 & 48 & $55 b$ \\
\hline $\mathrm{LE} 1^{(2)}$ & 270 & 330 & 88 & 59 & 89 & $103 \mathrm{~b}$ & 486 & 644 & 55 & $64 \mathrm{ab}$ \\
\hline LE2 & 298 & 219 & 92 & 71 & 84 & $104 \mathrm{ab}$ & 475 & 697 & 46 & $59 \mathrm{ab}$ \\
\hline LE3 & 291 & 275 & 84 & 55 & 84 & $99 b$ & 479 & 660 & 52 & $56 \mathrm{ab}$ \\
\hline LE4 & 284 & 229 & 62 & 63 & 85 & $90 \mathrm{bc}$ & 499 & 623 & 46 & $56 \mathrm{ab}$ \\
\hline $\mathrm{FM}^{(3)}$ & 261 & 178 & 80 & 81 & 90 & $119 a$ & 483 & 697 & 49 & $67 a$ \\
\hline FM2 & 281 & 328 & 65 & 73 & 98 & $101 b$ & 511 & 613 & 56 & $53 \mathrm{bc}$ \\
\hline FM3 & 382 & 314 & 64 & 66 & 93 & $104 a b$ & 494 & 605 & 53 & $53 \mathrm{bc}$ \\
\hline FM4 & 299 & 224 & 81 & 69 & 89 & $82 c$ & 506 & 624 & 54 & $42 c$ \\
\hline $\mathrm{CV}(\%)$ & 34 & 32 & 16 & 21 & 9 & 8 & 8 & 8 & 17 & 12 \\
\hline
\end{tabular}

${ }^{(1)}$ Valores seguidos de mesma letra não diferem entre si pelo teste Duncan, a 5\% de probabilidade. ${ }^{(2)} \mathrm{Lodo}$ de esgoto: LE1, $1,5 \mathrm{Mg}$ ha-1; $\mathrm{LE}^{2}, 3,0 \mathrm{Mg}$ ha-1; LE3, 4,5 $\mathrm{Mg} \mathrm{ha}^{-1}$; LE4, 6,0 $\mathrm{Mg} \mathrm{ha}^{-1}$. ${ }^{(3)}$ Fertilizante mineral (N; $\mathrm{P}_{2} \mathrm{O}_{5}$; K $\mathrm{O}_{2}$ ): FM1, 99-101-7 kg ha-1; FM2, 196-200-14 kg ha ${ }^{-1}$; FM3, 295-301-22 kg ha-1; FM4, 393-402-29 $\mathrm{kg} \mathrm{ha}^{-1}$. 
de fertilizante mineral. Foram observadas reduções no $\mathrm{CBM}$, na profundidade de 0 a $5 \mathrm{~cm}$, e na atividade da beta-glicosidase, nas profundidades de 0 a $5 \mathrm{~cm}$ e 5 a $20 \mathrm{~cm}$, na dose 1 do lodo de esgoto (LE1) (Tabela 5). A aplicação dessa dose de lodo também causou aumento do CBM na profundidade de 5 a $20 \mathrm{~cm}$. A dose 3 do lodo de esgoto (LE3) aumentou a atividade da beta-glicosidase, na profundidade 0 a $5 \mathrm{~cm}$, enquanto a dose 4 (LE4) aumentou a atividade da fosfatase. Na profundidade de 5 a $20 \mathrm{~cm}$, a dose 2 do lodo (LE2) aumentou o C mineralizável e a dose 4 (LE4), a atividade da arilsulfatase.

Da mesma forma que o esgotamento dos nutrientes na dose 1 do lodo de esgoto (LE1) resultou em reduções no rendimento de grãos da soja, as reduções pontuais no CBM e na atividade da enzima beta-glicosidase, na profundidade de 0 a $5 \mathrm{~cm}$, também podem ser atribuídas à escassez de substratos carbonados para as populações microbianas do solo. Essa explicação está baseada no fato de que o aumento das doses de lodo de esgoto não implicou reduções nos atributos biológicos avaliados neste trabalho. Crecchio et al. (2001) observaram aumentos na atividade da enzima beta-glicosidase nos tratamentos que continham as maiores doses de lodo, e relacionaram esses aumentos ao maior fornecimento de substratos carbonados no solo via lodo de esgoto. Pascual et al. (1999) e García-Gil et al. (2004) também reportaram incrementos na atividade enzimática em resposta à aplicação de lodo de esgoto. Entretanto, doses relativamente altas de lodo de esgoto $\left(>20 \mathrm{Mg} \mathrm{ha}^{-1}\right)$ foram empregadas nesses dois trabalhos e, portanto, seus resultados não podem ser extrapolados para situações nas quais o lodo é aplicado apenas uma vez e em baixas quantidades.

Trannin et al. (2007), ao estudar a resposta à aplicação de biossólido industrial no cultivo de milho, concluíram que, mesmo após dois anos consecutivos da aplicação de doses de até $24 \mathrm{Mg} \mathrm{ha}^{-1}$, foram constatados incrementos na maioria das características biológicas relacionadas à fertilidade do solo, como $\mathrm{C}$ e $\mathrm{N}$ da biomassa microbiana, respiração basal e as atividades das enzimas urease e beta-glicosidase e da hidrólise do diacetato de fluoresceína (FDA). Esses autores afirmaram que os resultados favoráveis da aplicação do biossólido sobre características biológicas indicadoras de qualidade do solo foram devidos ao elevado teor de matéria orgânica e de nutrientes e ao baixo teor de metais pesados desse resíduo.

O tipo de resposta em relação à aplicação do lodo de esgoto está associado à qualidade e à quantidade do material aplicado. Os dados apresentados no presente trabalho mostram que as doses de lodo de esgoto utilizadas em uma única aplicação não afetaram negativamente os atributos biológicos avaliados, provavelmente em razão da ausência de agentes nocivos à microbiota no lodo gerado pela Caesb (Luduvice, 2000; Lemainski \& Silva, 2006a, 2006b). Ao mesmo tempo, a ausência de incrementos generalizados nos atributos biológicos do solo - como pode ser observado na análise de contraste entre LE x FM, não significativa

Tabela 5. Contrastes estimadas para os indicadores biológicos avaliados nos anos agrícolas 2004/2005 e 2005/2006 em amostras de um Latossolo Vermelho de Cerrado, submetido à adubação com lodo de esgoto e fertilizante mineral, apenas no primeiro ano de cultivo, coletadas nas profundidades de 0 a $5 \mathrm{~cm}$ e de 5 a $20 \mathrm{~cm}$.

\begin{tabular}{|c|c|c|c|c|c|c|c|c|c|c|}
\hline \multirow[t]{2}{*}{ Tratamento $^{(1)}$} & \multicolumn{2}{|c|}{$\mathrm{CBM}^{(2)}$} & \multicolumn{2}{|c|}{ C-mineralizável ${ }^{(3)}$} & \multicolumn{2}{|c|}{ Beta-glicosidase } & \multicolumn{2}{|c|}{ Fosfatase ácida } & \multicolumn{2}{|c|}{ Arilsulfatase } \\
\hline & $1^{\underline{o}}$ ano & $2^{\circ}$ ano & $1^{\circ}$ ano & $2^{\circ}$ ano & $1^{\circ}$ ano & $2^{\underline{0}}$ ano & $1^{\circ}$ ano & $2^{\circ}$ ano & $1^{\circ}$ ano & $2^{\circ}$ ano \\
\hline & \multicolumn{10}{|c|}{0 a $5 \mathrm{~cm}$} \\
\hline LE1 vs. FM1 & -39 & $-125^{*}$ & -19 & 7 & 6 & $-31 * *$ & 67 & -17 & 4 & -3 \\
\hline LE2 vs. FM2 & -42 & 14 & 8 & 23 & 4 & 14 & 23 & 54 & 8 & 0 \\
\hline LE3 vs. FM3 & 40 & 141 & 12 & 1 & -7 & $26 * *$ & -58 & 54 & -3 & 1 \\
\hline LE4 vs. FM4 & 49 & 22 & 13 & 6 & -4 & 4 & -53 & $111 * *$ & -10 & 6 \\
\hline LE vs. FM & 2 & 13 & 4 & 9 & 0 & 3 & -5 & $51 * *$ & 0 & 1 \\
\hline & \multicolumn{10}{|c|}{5 a $20 \mathrm{~cm}$} \\
\hline LE1 vs. FM1 & 8 & $141^{*}$ & 8 & -22 & -1 & $-16^{*}$ & 3 & -53 & 6 & -3 \\
\hline LE2 vs. FM2 & 20 & -94 & $27 *$ & -2 & -14 & 3 & -36 & 84 & -10 & 6 \\
\hline LE3 vs. FM3 & -84 & -33 & 20 & -11 & -9 & -5 & -15 & 55 & -1 & 3 \\
\hline LE4 vs. FM4 & -15 & 5 & -19 & -6 & -4 & 8 & -7 & -1 & -8 & $14 * *$ \\
\hline LE vs. FM & -18 & 5 & 9 & -10 & -7 & -3 & -14 & 21 & -3 & 5 \\
\hline
\end{tabular}

(1)Lodo de esgoto: LE1, 1,5 Mg ha-1 ${ }^{-1}$ LE2, 3,0 $\mathrm{Mg} \mathrm{ha}^{-1}$; LE3, 4,5 $\mathrm{Mg} \mathrm{ha}^{-1}$; LE4, 6,0 $\mathrm{Mg}^{-1}$ ha fertilizante mineral $\left(\mathrm{N} ; \mathrm{P}_{2} \mathrm{O}_{5}\right.$; $\left.\mathrm{K}_{2} \mathrm{O}\right)$ : FM1, 99-101-7 kg ha-1; FM2, 196-200-14 kg ha ${ }^{-1}$; FM3, 295-301-22 $\mathrm{kg} \mathrm{ha}^{-1}$; FM4, 393-402-29 $\mathrm{kg} \mathrm{ha}^{-1} .{ }^{\left({ }^{2}\right)}$ Carbono da biomassa microbiana do solo. ${ }^{(3)} \mathrm{Carbono}$ prontamente

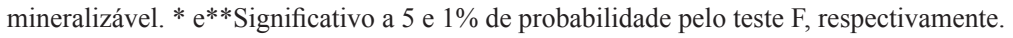


para todos os atributos microbiológicos à exceção da fosfatase ácida, na profundidade de 0 a $5 \mathrm{~cm}$ (Tabela 5) - também reflete o fato de que as doses de lodo de esgoto avaliadas no presente trabalho não foram suficientes para aumentar o aporte de material orgânico ao solo a ponto de estimular o crescimento de sua biomassa e sua atividade microbiana. Novos estudos, incluindo avaliações de longo prazo e aplicações sucessivas do lodo de esgoto da Caesb, serão importantes para avaliar seus efeitos no funcionamento do solo.

\section{Conclusões}

1. Uma aplicação do lodo de esgoto gerado pela Caesb, em doses de até $6 \mathrm{Mg} \mathrm{ha}^{-1}$, não afeta negativamente a nodulação da soja no período de dois anos.

2. Com exceção da dose de $1,5 \mathrm{Mg} \mathrm{ha}^{-1}$, as demais doses de lodo de esgoto da Caesb (3, 4, 5 e $\left.6 \mathrm{Mg} \mathrm{ha}^{-1}\right)$ proporcionam rendimento de grãos semelhante ao que se obtém com quantidades equivalentes de nitrogênio, fósforo e potássio no fertilizante mineral.

3. Uma aplicação de até $6 \mathrm{Mg} \mathrm{ha}^{-1}$ do lodo de esgoto da Caesb não apresenta efeitos significativos no carbono da biomassa microbiana, no carbono prontamente mineralizável e na atividade das enzimas beta-glicosidase, arilsulfatase e fosfatase ácida no período de dois anos.

\section{Referências}

ARAUJO, F.F. de. Efeito do lodo de esgoto sobre a nutrição, nodulação e doenças da soja. 2003. Tese (Doutorado) Universidade Estadual Paulista, São Paulo.

BETTIOL, W.; CAMARGO, O.A. (Ed.). Impacto ambiental do uso agrícola do lodo de esgoto. Jaguariúna: Embrapa Meio Ambiente, 2000. 312p.

BOEIRA, R.C.; LIGO, M.A.V.; DYNIA, J.F. Mineralização de nitrogênio em solo tropical tratado com lodos de esgoto. Pesquisa Agropecuária Brasileira, v.37, p.1639-1647, 2002.

BOEIRA, R.C.; MAXIMILIANO, V.C.B. Determinação da fração de mineralização de nitrogênio de lodos de esgoto: um método alternativo. Jaguariúna: Embrapa Meio Ambiente, 2004. (Embrapa Meio-Norte. Comunicado Técnico 13).

BRASIL. Resolução Conama n⿳⺈ 375, de 29 de agosto de 2006. Define critérios e procedimentos, para o uso agrícola de lodos de esgoto gerados em estações de tratamento de esgoto sanitário e seus produtos derivados, e dá outras providências. Diário Oficial [da] República Federativa do Brasil, 30 ago. 2006. Seção 1, p.141-146.
CASTILHOS, D.D.; GUADAGNIN, C.A.; SILVA, M.D. da; LEITZKE, V.W.; FERREIRA, L.H.; NUNES, M.C. Acúmulo de cromo e seus efeitos na fixação biológica de nitrogênio e absorção de nutrientes em soja. Revista Brasileira de Agrociência, v.7, p.121-124, 2001.

CLAESSEN, M.E.C. (Org.). Manual de métodos de análise de solo. 2.ed. rev. atual. Rio de Janeiro: Embrapa-CNPS, 1997. 212p. (Embrapa-CNPS. Documentos, 1).

CRECCHIO, C.; CURCI, M.; MININNI, R.; RICCIUTI, P.; RUGGIERO, P. Short-term effects of municipal solid waste compost amendments on soil carbon and nitrogen content, some enzyme activities and genetic diversity. Biology and Fertility of Soils, v.34, p.311-318, 2001.

CURRIE, V.C.; ANGLE, J.S.; HILL, R.L. Biosolids application to soybeans and effects on input and output of nitrogen. Agriculture, Ecosystems and Environment, v.97, p.345-351, 2003.

DAR, H.G. Effects of cadmium and sewage-sludge on soil microbial biomass and enzyme activities. Bioresource Technology, v.56, p.141-145, 1996.

FERNANDES, S.A.P.; BETTIOL, W.; CERRI, C.C. Effect of sewage sludge on microbial biomass, basal respiration, metabolic quotient and soil enzymatic activity. Applied Soil Ecology, v.30, p.65-77, 2005.

GARCÍA-GIL, J.C.; PLAZA, C.; SENESI, N.; BRUNETTI, G.; POLO, A. Effects of sewage sludge amendment on humic acids and microbiological properties of a semiarid Mediterranean soil. Biology and Fertility of Soils, v.39, p.320-328, 2004.

GUEDES, M.C.; ANDRADE, C.A. de; POGGIANI, F.; MATTIAZZO, M.E. Propriedades químicas do solo e nutrição do eucalipto em função da aplicação de lodo de esgoto. Revista Brasileira de Ciência do Solo, v.30, p.267-280, 2006.

KIZILKAYA, R.; BAYRAKLI, B. Effects of N-enriched sewage sludge on soil enzyme activities. Applied Soil Ecology, v.30, p.192-202, 2005.

KOUTROUBRAS, S.D.; PAPAKOSTA, D.K.; GAGIANAS, A.A. The importance of early dry matter and nitrogen accumulation in soybean yield. European Journal of Agronomy, v.9, p.1-10, 1998.

LEMAINSKI, J.; SILVA, J.E. da. Avaliação agronômica e econômica da aplicação de biossólido na produção de soja. Pesquisa Agropecuária Brasileira, v.41, p.1477-1484, 2006 a.

LEMAINSKI, J.; SILVA, J.E. da. Utilização do biossólido da CAESB na produção de milho no Distrito Federal. Revista Brasileira de Ciência do Solo, v.30, p.741-750, 2006 b.

LUDUVICE, M. Experiência da companhia de saneamento do Distrito Federal na reciclagem agrícola de biossólido. In: BETTIOL, W.; CAMARGO, O.A. de (Ed.). Impacto ambiental do uso agrícola do lodo de esgoto. Jaguariúna: Embrapa Meio Ambiente, 2000. p.153-162.

MADARIAGA, G.M.; ANGLE, J.S. Sludge-borne salt effects on survival of Bradyrhizobium japonicum. Journal of Environmental Quality, v.21, p.276-280, 1992. 
MENDES, I.C.; HUNGRIA, M.; VARGAS, M.A.T. Soybean response to starter nitrogen and Bradyrhizobium inoculation on a Cerrado Oxisol under no-tillage and conventional tillage systems. Revista Brasileira de Ciência do Solo, v.27, p.81-87, 2003.

MORENO, J.L.; GARCÍA, C.; HERNÁNDEZ, T. Changes in organic matter and enzymatic activity of an agricultural soil amended with metal-contaminated sewage sludge compost. Communications in Soil Science and Plant Analysis, v.29, p.2247-2262, 1998.

OLIVEIRA, J.R.A.; MENDES, I.C.; VIVALDI, L. Carbono da biomassa microbiana em solos de cerrado sob vegetação nativa e sob cultivo: avaliação dos métodos fumigação-incubação e fumigação-extração. Revista Brasileira de Ciência do Solo, v.25, p.863-871, 2001.

PASCUAL, J.A.; GARCÍA, C.; HERNANDEZ, T. Lasting microbiological and biochemical effects of the addition of municipal solid waste to an arid soil. Biology and Fertility of Soils, v.30, p.1-6, 1999.

REVOREDO, M.D.; MELO, W.J. de. Enzyme activity and microbial biomass in an Oxisol amended with sewage sludge contaminated with nickel. Scientia Agricola, v.64, p.61-67, 2007.

ROCHA, G.N.; GONÇALVES, J.L.M.; MOURA, I.M. Mudanças da fertilidade do solo e crescimento de um povoamento de Eucalyptus grandis fertilizado com biossólido. Revista Brasileira de Ciência do Solo, v.28, p.623-639, 2004.

SAS INSTITUTE. SAS/STAT: user's guide. Version 6. Cary: SAS Institute, 1996. 1686p.

SASTRE, I.; VICENTE, M.A.; LOBO, M.C. Influence of the application of sewage sludges on soil microbial activity. Bioresource Technology, v.57, p.19-23, 1996.

SILVA, J.E.; RESCK, D.V.S.; SHARMA, R.D. Alternativa agronômica para o biossólido produzido no Distrito Federal. II Aspectos qualitativos, econômicos e práticos de seu uso. Revista Brasileira de Ciência do Solo, v.26, p.497-503, 2002a.

SILVA, J.E.; RESCK, D.V.S.; SHARMA, R.D. Alternativa agronômica para o biossólido produzido no Distrito Federal. I Efeito na produção de milho e na adição de metais pesados em
Latossolo no Cerrado. Revista Brasileira de Ciência do Solo, v.26, p.487-495, 2002b.

SOARES, E.M.B. Impacto de aplicações sucessivas de lodo de esgoto sobre os compartimentos de carbono orgânico em Latossolo cultivado com milho. 2005. 84p. Dissertação (Mestrado) - Universidade Federal de Lavras, Lavras.

SULLIVAN, T.S.; STROMBERGER, M.E.; PASCHKE, M.W.; IPPOLITO, J.A. Long-term impacts of infrequent biosolids applications on chemical and microbial properties of a semi-arid rangeland soil. Biology and Fertility of Soils, v.42, p.258-266, 2006.

TABATABAI, M.A. Soil enzymes. In: WEAVER, R.W.; ANGLE, S.; BOTTOMLEY, P.; BEZDICEK, D.; SMITH, S.; TABATABAI, A.; WOLLUM, A. (Ed.). Methods of soil analysis: microbiological and biochemical properties. Madison: Soil Science Society of America, 1994. p.775-833. (Soil Science Society of America series, 5).

TRANNIN, I.C. de B.; SIQUEIRA, J.O.; MOREIRA, F.M. de S. Atributos químicos e físicos de um solo tratado com biossólido industrial e cultivado com milho. Revista Brasileira de Engenharia Agrícola e Ambiental, v.12, p.223-230, 2008.

TRANNIN, I.C. de B.; SIQUEIRA, J.O.; MOREIRA, F.M. de S. Avaliação agronômica de um biossólido industrial para a cultura do milho. Pesquisa Agropecuária Brasileira, v.40, p.261-269, 2005.

TRANNIN, I.C. de B.; SIQUEIRA, J.O.; MOREIRA, F.M. de S. Características biológicas do solo indicadoras de qualidade após dois anos de aplicação de biossólido industrial e cultivo de milho. Revista Brasileira de Ciência do Solo, v.31, p.1173-1184, 2007.

VANCE, E.D.; BROOKES, P.C.; JENKINSON, D.S. An extraction method for measuring soil microbial biomass C. Soil Biology \& Biochemistry, v.19, p.703-707, 1987.

VIEIRA, R.F. Sewage sludge effects on soybean growth and nitrogen fixation. Biology and Fertility of Soils, v.34, p.196-200, 2001.

VIEIRA, R.F.; TANAKA, R.T.; SILVA, C.M.M.S. Utilização do lodo de esgoto na cultura da soja. Jaguariúna: Embrapa Meio Ambiente, 2004. 26p. (Embrapa Meio Ambiente. Boletim de Pesquisa e Desenvolvimento, 21).

Recebido em 31 de março de 2009 e aprovado em 21 de setembro de 2009 